\title{
Housing Cycles in Switzerland - A Time-Varying Approach
}

Working Paper

Author(s):

Drechsel, Dirk

Publication date:

2015-05

Permanent link:

https://doi.org/10.3929/ethz-a-010431888

Rights / license:

In Copyright - Non-Commercial Use Permitted

Originally published in:

KOF Working Papers 381 


\section{KOF Working Papers}

Housing Cycles in Switzerland - A Time-Varying Approach

Dirk Drechsel 


\section{KOF}

KOF Swiss Economic Institute

ETH Zurich

LEE G 116

Leonhardstrasse 21

8092 Zurich

Switzerland

Phone +41446324239

Fax +41446321218

www.kof.ethz.ch

kof@kof.ethz.ch 


\title{
Housing Cycles in Switzerland - A Time-Varying Approach
}

\author{
Dirk Drechsel*
}

May 4, 2015

Preliminary Version

\begin{abstract}
In light of the strong increase of house prices in Switzerland, we analyze the effects of mortgage rate shocks, changes in the interplay between housing demand and supply and GDP growth on house prices for the time period 19812014. We employ Bayesian time-varying coefficients vector autoregressions to allow different monetary and immigration regimes over time. A number of structural changes, such as regulatory changes in the aftermath of the 1990s real estate crisis, the introduction of free-labor movements in the 2000s or the zero lower bound interest rate regime in the 2010s might have affected the responses of house prices to influencing factors. We investigate potential parameter changes and their importance in light of the current housing price boom. We find that $40 \%$ of house price variations can be explained by changes in demand and supply for housing. Furthermore, the response of house prices to mortgage rate shocks weakened after the 1990s real estate crisis and increased in size again during the recent house price boom.
\end{abstract}

JEL classifications: C32, R21, R31

Keywords: Switzerland, house prices, time-varying VAR

*I am grateful to Klaus Abberger and Samad Sarferaz for helpful comments and discussions. I further thank Florian Eckert for valuable research assistance and seminar participants at ETH Zurich for helpful comments. Author's address: KOF Swiss Economic Institute, ETH Zurich, Leonhardstrasse 21 LEE, CH-8092 Zurich, Switzerland. Author's e-mail: drechsel@kof.ethz.ch. 


\section{Introduction}

In current times there is growing concern that the Swiss residential market is overheating and might already find itself in a bubble. These concerns are based on the rapid growth residential house prices have displayed in the last years. Housing prices are starting to resemble the development they went through in the late 80's and early 90's when the exaggerated inflation of residential prices ended in a bust of housing markets. An important question when dealing with a booming residential market is to determine to which extent the current price movements can be explained by the development of fundamentals (financing conditions, supply \& demand for housing, business cycle conditions). Changes in these fundamentals might trigger price reactions. The influence of these fundamentals might change over time.

A number of policy interventions currently aim at influencing factors of a housing boom: Immigration levels shall be controlled from 2017 onwards, macroprudential measures addressing mortgages aim to foster resilience of the banking sector and of borrowers to real estate shocks. ${ }^{1}$. At the same time mortgage rates reached all time lows in consequence to a lowering of LIBOR target rates by the Swiss National Bank into negative territories. ${ }^{2}$ Mortgage rates at some banks dropped to historically low rates of 1,5\%. Various planning acts (Zweitwohnungsinitiative, Raumplanungsgesetze) aim to reduce new construction outside settled areas. Furthermore, the strong appreciation of the Swiss Franc in consequence to the lower bound repeal on January 15th 2015 might reduce GDP growth.

In order to assess the effects of different shocks on the development of house prices we employ time-varying coefficients vectorautoregressions. How important are innovations to the mortgage rate, to population growth, to construction, to GDP growth important for house price developments? Did their influence change over time? Vectorautoregessions (VAR) allow to investigate the effects of causal shocks to the economic system, all variables are treated as being endogenous. VARs provide a plausible assessment of the response of macroeconomic variables to different kinds of shocks, such as monetary policy or demography, without requiring a complete structural model of the economy. Studies on causal effects for house prices in Switzerland so far do not utilize time-varying coefficients, thereby ignoring the possibility that parameters changed over the last decades. In order to capture changes in correlations and parameters we employ time-varying methods. The time period considered ranges from 1981 to 2014. Structural breaks during these three decades are to be expected. These structural changes can affect the assumption of constant cyclical and monetary circumstances. Time-varying parameters absorb these structural breaks, leading to cyclical and monetary circumstances being specific for each point in time. Time-varying methods have the advantage that they can utilize the full data set, if certain sub-periods are of interest. Such subperiods are the decade prior to the Swiss real estate crisis, the decade after the crisis until the financial

\footnotetext{
${ }^{1}$ Such interventions might also influence mortgage rates

${ }^{2}$ The recent repeal of the Swiss Franc/Euro exchange rate lower bound on January 15th 2015 came together with a lowering of the interest band into negative territories.
} 
crisis, and the years since then. ${ }^{3}$

Furthermore, the period after the recent financial crisis has not been studied so far. This period has been characterized by a very low interest regime and strong population growth, accompanied by strongly rising house prices in Switzerland, which lead to fears about a real estate bubble building up.

The causal shocks to be studied are unanticipated shocks to the interplay of housing demand and supply, to mortgage financing conditions (i.e. user costs of housing) ${ }^{4}$, to house price developments and to economic growth. By explicitly focusing on the interplay of housing supply and demand we incorporate features of stock-flow models ${ }^{5}$ into an endogenous vectorautoregressive setup. The difference between population growth and housing stock growth is taken as an indicator for excessive demand or oversupply for housing. It is of interest to use excessive supply (or excessive demand) to explain house price developments. Large immigration flows which lead to high population growth themselves might have only a minor effect on housing prices if supply is enlarged simultaneously. Only if a mismatch between supply and demand exists shortages (or excessive supply vice versa) might lead to substantial house price movements. The current interest rate regime (negative interest rates) differs from the interest rate regimes experienced in the 1980s and 1990s. So does population growth. As a consequence to the full introduction of the free labor movement agreement with the European Union immigration numbers have risen strongly since 2007, while net migration in the mid 1990s basically was zero. Different regimes might lead to different parameters describing the relationships among influencing factors over time.

Other structural changes which might have triggered parameter changes regarding the variables of investigation were the changes in monetary regimes employed by the Swiss National bank, different regulatory settings for mortgage loans such as Basel I and Basel II alongside the introduction of sophisticated risk management systems, the introduction of real estate transfer taxes in 1992, housing construction subsidies by the federal government in 1993, the real estate crisis in the early 1990s, the implementation of different steps towards free labor movement within Europe

\footnotetext{
${ }^{3}$ House prices have been rising in Switzerland since the late 1990s. Prior to the recent increase in house prices Switzerland faced a real estate crisis in the 1990s. Before the 1990's real estate crisis the Swiss housing market was experiencing a boom throughout the 1980s.

${ }^{4}$ Hott and Monnin (2008) study how long Swiss real estate prices deviate from their fundamental vales. Fundamental values are determined by a rent (i.e. housing cost and return) and a supply/demand model as a function of household income and construction.

${ }^{5}$ Investigations of Swiss construction and housing markets Steiner (2010), employing a stock-flow framework showed, that a mismatch between desired level of residential capital stock and existing residential capital stock can diverge for some years. Therefore, imbalances have to be adjusted via prices, a surplus in housing leads to falling house prices, a housing shortage leads to rising house prices. Switzerland displays one of the most inelastic short run housing supply curves worldwide. This means that shifts in demand are almost exclusively traduced into changes in residential prices. Steiner finds, that housing prices are an important determinant for the evolution of residential investment, as well as cost shifting variables such as construction costs and mortgage rates. Her results show, that one third of the mismatch between existing and desired residential capital stock will be corrected in the following year.
} 
(treaty signed 1999, first step 2002, full liberalization 2007), the introduction of macroprudential measures restricting mortgage lending since 2012, the prohibition of vacation home construction in tourist regions with a share of more than $20 \%$ second homes alongside various land-use planning acts since 2013.

Only a few, yet time-invariant analyses highlight the endogenous nature of influencing factors and residential prices studying Switzerland. ${ }^{6}$ Using vectorautoregressions Berlemann and Freese (2013) on a sample ranging from 1987-2008 find that positive interest rate shocks have adverse effects on house and condominium prices. They provide a nice overview of the Swiss real estate market. In contrast to their approach we include the interplay between demand and supply and investigate changes over time to accomodate for different monetary, demographic and regulatory regimes. Borowiecki (2009) also studied Swiss construction in the long run. He used annual observations for 17 years. The author finds that house price growth and construction activity react to changes in population and to construction prices, GDP is mentioned to have no effect. House price shocks have no long-term impact on housing supply and vice-versa. Alas, given the short horizon, the confidence intervals for his impulse responses are very wide. Degen and Fischer (2009) have studied the effect of immigration on Swiss house prices using immigration flows for 85 districts from 2001 to 2006, finding an effect of 2,7\%. Further investigations on Swiss housing market have been conducted by Bourassa, Hoesli, and Scognamiglio (2010) and Brown and Guin (2013).

We find that $40 \%$ of house price variations can be explained by changes in the match between housing demand and supply. Furthermore, the response of house prices to mortgage rate shocks weakened after the 1990s real estate crisis and increased in size again during the recent house price boom. Fluctuations in GDP growth only play a minor role compared to movements in mortgage rates or changes in excess supply.

The remainder is structured as follows: After a description of the data used, a short introduction into time-varying VARs will be presented. The results will be displayed and described, the article concludes with a summary of results and findings.

\footnotetext{
${ }^{6}$ Data on Swiss house prices has been included in a number of panel VAR studies. Using data for 1971-2006 including Switzerland Goodhart and Hofmann (2008) as well as Assenmacher and Gerlach (2008) find a persistent effect of an interest rate shock on house prices, even ten years after the shock. Furthermore they find a substantial response of house prices to a shock in GDP, which only looses significance ten years after the shock. Goodhart and Hofman find a relevant influence of a GDP shock on house prices in general, based on their 17 countries sample from 1971-2006. controlling house price booms, GDP growth does not matter in normal times. On average they also report a significant influence of an interest rate shock on house prices, which also appears to be persistent. Impulse responses depict the -country independent- average effect, using country fixed effects. It is difficult to infer results for single countries using Panel VARs, homogeneity assumptions of results would be required. As Tsatsaronis and Zhu (2004) Show, there is significant variation across countries in both business practices and the regulatory framework for mortgage finance, which influences mortgage rates and thereby user costs of housing. Excess liquidity and the effects on house prices including Swiss data in a global VAR has also been studied by Belke and Orth (2007).
} 


\section{Data}

Data considered in the analysis refer to apartment prices, GDP growth, a mismatch between housing supply and demand as well as mortgage rates.

The match between housing demand (population growth) and housing supply (housing stock growth) is measured as the difference between population growth rates and housing stock growth rates. In the following, such a difference between growth rates will be named housing demand \& supply ratio. Data on population are taken from Swiss statistical office. The population number is the total population by the end of the year.

The housing stock in 1980 has been derived by the vacancy rate and the number of unoccupied apartments in 1980 as provided by the Swiss statistical office ${ }^{7}$. The vacancy rate and the number of unoccupied apartments are vacancies in relation to the housing stock of the previous year. Updates of housing stock are based on net increases of housing stock as published by the statisctical office ${ }^{8}$. Housing stock is taken as Q4 value. Quarterly values for population and housing stock have been interpolated by using a cubic spline.

Data on quarterly real GDP is taken from Swiss statistical office and Swiss secretariat for economic affairs (SECO). GDP is a proxy for the business cycle and household income. As a proxy for house prices the series of apartment prices as published by Swiss National Bank and Wüest \& Partner has been chosen. Robustness checks with time series on single-family dwellings and multi-family rental buildings have been conducted and yielded similar results. House prices have been deflated using CPI, as published by the Swiss Statistical Office. Growth rates for population and housing stock and GDP are calculated as quarter-over-previous-year-quarter growth rates to eliminate seasonal effects.

Mortgage rates are middle rates for new mortgages as provided by Zurich Cantonal Bank (ZKB). Relative mortgage rate developments (calculated as quarterover-previous-year-quarter growth rates) have been taken to proxy user costs. The major variable depicting the development of user costs of housing are mortgage rates (see for instance DiPasquale and Wheaton (1994), Steiner (2010) or Hott and Monnin (2008).). The relative increase in mortgage rates is relevant to judge changes in user costs and affordability of housing purchases. A lower user cost of housing would consequently justify higher house prices.

The data set ranges from 1981-2014. Due to the calculation of growth rates the time period considered ranges from 1982 to 2014. The development of house prices, excessive demand or (oversupply of housing vice versa), mortgage rate changes and GDP growth have undergone strong swings during the last three and a half decades

\footnotetext{
${ }^{7}$ Vacancy rate, table je-d-09.02.02.03.01 in Bau- und Wohnungswesen 2012, Swiss statistical office, Neuchatel, published 2014

${ }^{8}$ Annual new construction and refurbishments of apartments, table je-d-09.02.02.01 in Bau- und Wohnungswesen 2012, Swiss statistical office, Neuchatel, published 2014
} 
(see figure 1).

[[ Figure 1 to be inserted here. ]]

By looking at figure 1 it can be observed, that house price developments since the early 1980s can be divided into four subperiods. Until the end of the 1980s apartment prices rose strongly, reaching quarter-over-previous-year-quarter growth rates of up to $10 \%$. Starting in the late 1980s house prices first started to stagnate and declined strongly until the late 1990s. Reductions in house prices by $10 \%$ in comparison to the previous' years quarter can be observed. In the late 1990s house prices started to recover and grew until the early 2000s. From the early 2000s until 2007 apartment prices almost stagnated with very low growth rates. Since 2007 house prices rose strongly again, with a declining trend in growth rates at the end of the sample.

Mortgage rates were subject to substantial swings during the sample period. With the change in the monetary regime settings of the Swiss National Bank by the end of the 1980s and in consequence to imported inflation from Germany after the reunification nominal interest rates rose sharply. Consequently mortgage rates were affected. In relative terms the user costs of housing, i.e. the monthly interest payment costs, rose by up to $30 \%$ in quarter-over-previous-year-quarter comparison. During the early 1990s, when house prices deteriorated, Switzerland entered a recession and the banking sector experienced financial turmoil. ${ }^{9}$ Interest rates and consequently mortgage rates rates were lowered again, leading to a reduction in user costs by up to $25 \%$. Only by the end of the 1990s mortgage rates rose again, before declining substantially in the wake of the dot.com turmoil. Prior to the financial crisis interest and mortgage rates rose again in 2006/2007, before decreasing to record low levels - single 10 year mortgages were available at 1.5\% in January 2015.

In the majority of time periods between 1982 and 2014 the growth rate of housing stock exceeded the population growth rate. New construction also incorporates new vacation homes. At the same time during the last decades, the number of persons living in each apartment has declined steadily. The dynamics of the series show the strong increase in population during the 1980s, being caused by a substantial migration inflow. During the early 1990s immigration numbers dwindled, while housing production - being especially subsidized by federal government in 1993 reached a peak in 1994. Declining numbers of immigrants with expanding housing stock lead to an oversupply in housing by the mid 1990s. With the construction industry facing headwind and lowering production in the second half of the 1990s, the economy recovering and a rising number of immigrants the oversupply was reduced. During the first half of the 2000s housing stock expansion was again stronger than population growth, while since 2007 - the year of the full fledged implementation of free labor movement - population growth rates exceeded housing stock expansion rates.

\footnotetext{
${ }^{9} \mathrm{~A}$ bank run on Spar- und Leihkasse Thun, troubles in cantonal banks Solothurn, Berne and Appenzell-Innerrhoden, as well as for Volksbank and several regional banks.
} 
Turning to GDP, the Swiss economy was expanding strongly in the 1980s after the second oil crisis. In the early 1990s the Swiss economy went into a recession and stagnated until 1997. During the dot.com boom years the economy expanded again while experiencing zero growth in 2002. Up until the onset of the 2007-2009 financial crisis the Swiss economy was expanding strongly, followed by a decline during the financial crisis and moderate growth rates afterwards.

\section{Method}

Vector autoregressive models treat variables of an estimation system as endogenous, meaning that all changes of individual variables affect the entire system and are at the same time endogenously affected by the follow-up reactions. All endogenous variables are interdependent. Utilizing Bayesian methods, the estimation utilizes a multiplication of prior and likelihood density functions. To interpret the parameter estimation, it is possible to use impulse response functions. A shock in a variable (a sudden, unexpected change, i.e. an impulse) in this application is by statistical definition independent from shocks that affect other variables. Specifically this implies that a shock in monetary policy (for instance a mortgage rate decrease) is not correlated with exogenous innovations in GDP growth, housing demand/supply or residential prices. Reactions to shocks (impulse response functions) can therefore be considered individually. It is possible to observe the impact of these exogenous shocks on the system over the course of time. The method of time-varying parameters allows for an investigation of time-dependent causal effects. Considering periods individually, it becomes possible to detect changes in the responses to economic shocks over time.

Let $\boldsymbol{y}_{t}$ be $M \times 1$ vector containing $M$ variables at time $t$ which is part of a reduced form VAR representation ${ }^{10}$

$$
\boldsymbol{y}_{t}=\boldsymbol{\alpha}_{0, t}+\boldsymbol{\alpha}_{1, t} \boldsymbol{y}_{t-1}+\boldsymbol{\alpha}_{2, t} \boldsymbol{y}_{t-2}+\cdots+\boldsymbol{\alpha}_{p, t} \boldsymbol{y}_{t-p}+\boldsymbol{\epsilon}_{t}
$$

where $\alpha_{0, t}$ is a $M \times 1$ vector of time-varying intercepts, $\alpha_{i, t}$, for $\mathrm{i}=1, \ldots, \mathrm{p}$ are $M \times M$ matrices of time-varying coefficients with lag structure $p$ and $\epsilon_{t}$ is a $M \times 1$ Gaussian white noise process with zero mean and covariance $\Sigma$.

Rewriting the model in state space ${ }^{11}$ form and vectorizing expressions:

${ }^{10}$ The following short introduction into TVC-BVARs is based on Hamilton (1994), Del Negro and Schorfheide (2011), Gambetti (2005), Koop and Korobilis (2010) and Kim and Nelson (2003).

${ }^{11}$ The specific measurement and state equations are a special case of a general space state representation:

$$
\boldsymbol{y}_{t}=\boldsymbol{W}_{t} \boldsymbol{\delta}+\boldsymbol{Z}_{t} \boldsymbol{\theta}_{t}+\boldsymbol{\epsilon}_{t}
$$


Measurement equation:

$$
\boldsymbol{y}_{t}=\boldsymbol{X}_{t}^{\prime} \boldsymbol{\theta}_{t}+\boldsymbol{\epsilon}_{t}
$$

State equation:

$$
\boldsymbol{\theta}_{t+1}=\boldsymbol{\theta}_{t}+\boldsymbol{u}_{t+1}
$$

where $\boldsymbol{X}_{\boldsymbol{t}}^{\prime}=\boldsymbol{I}_{M} \otimes \boldsymbol{x}_{t}^{\prime}$ is a $M \times(M p+1) M$ matrix, with $\boldsymbol{I}_{M}$ representing a $M \times M$ identity matrix and $\boldsymbol{x}_{\boldsymbol{t}}^{\prime}=\left[1_{M}, \boldsymbol{y}_{t-1}^{\prime}, \boldsymbol{y}_{t-p}^{\prime}\right]$ with $1_{M}$ being a row vector of ones of length $M$. States $\boldsymbol{\theta}_{t}$ are assumed to follow a random walk and are described by $\boldsymbol{\theta}_{t}=$ $\operatorname{vec}\left(\boldsymbol{\alpha}_{t}^{\prime}\right)$. $\boldsymbol{u}_{t}$ collects the $\left.(M p+1) M \times 1\right)$ Gaussian white noise process independent of $\boldsymbol{\epsilon}_{t}$ with zero mean and covariance matrix $\Omega$.

Time-varying parameters can be estimated using the Kalman filter and smoother. The estimation takes place using Bayesian estimation procedures ${ }^{12}$.

Carter and Kohn (1994) have demonstrated how to use the Gibbs-sampler in order to infer $\boldsymbol{\Sigma}$ and $\boldsymbol{Q}$ from the posterior of $\boldsymbol{\beta}_{t}$, given the unknown but fixed parameters. The Gibbs-sampler is applied to deduce sequences ${ }^{13}$ from conditional distributions by the use of parameters calculated with the Kalman filter. This allows for an approximate calculation of a common probability distribution and eventually a determination of average (or median) parameter values.

Independent Normal-Wishart-priors are used as priors. They were chosen as diffuse as possible in the state equation in order for the variance to provide a sufficient flexibility of the state parameters. The entire sample was used as training sample because of the relative small number of observations. Starting values where retrieved

and

$$
\boldsymbol{\theta}_{t+1}=\boldsymbol{T}_{t} \boldsymbol{\theta}_{t}+\boldsymbol{u}_{t}
$$

whereby $\boldsymbol{W}_{t}$ represents a matrix with $M \times 1$ exogenous variables and $\boldsymbol{\delta}$ the corresponding parameter vector. The matrix $\boldsymbol{T}$ transforms the latently unknown parameters $\boldsymbol{\theta}_{t}$ into their next state $\boldsymbol{\theta}_{t+1} . \boldsymbol{T}$ is an identity matrix in this application. The error terms of the state equation are by definition normally distributed with $\boldsymbol{u}_{t} \sim N\left(\mathbf{0}, \boldsymbol{Q}_{t}\right)$, where $\boldsymbol{\epsilon}_{t}$ and $\boldsymbol{u}_{t}$ are independent from each other over all points of time. Variance-covariances $(\boldsymbol{\Sigma}, \boldsymbol{\Omega})$ are considered time-invariant.

${ }^{12}$ Alternative maximum-likelihood-estimation procedures require too much computing time compared to a repeated exertion of the filter to optimize the unknown parameters.

${ }^{13}$ Further parametric specifications: Lag-length is set to 2 , as an inclusion of lag length $>2$ would reduce the degrees of freedom too substantially. The number of draws is 100'000. Burn-in: Only the last 20'000 draws are used for the analysis (the first 80000 are discarded), of which only every tenth draw is saved and evaluated. Rejection Sampling: If the eigenvalue of the parameter-matrix leads to an explosive behavior of the impulse response function, the entire draw will be rejected. Convergence has been checked by plotting the trace of parameter values. 
by using OLS estimates.

Because of the endogeneity of variables it is difficult to interpret the parameters directly. An interpretation is usually done using a vector autoregressive moving average representation (VARMA), which allows for the derivation of impulse response functions. They represent the reactions of specific variables to an exogenous, orthogonal shock (innovation). This shock is by definition independent from other shocks. To ensure this independence, error terms and therefore the variance-covariance matrix have to be rewritten in a way that innovations do not correlate with other innovations. This is often done by decomposing the variance-covariance matrix, for instance with a Cholesky-decomposition. Doing so, contemporaneous zero restrictions are set.

The estimated variance-covariance matrix $\Sigma$ is decomposed by the Cholesky decomposition into $\boldsymbol{\Sigma}_{t}=\boldsymbol{A} \boldsymbol{D} \boldsymbol{A}^{\prime}=\boldsymbol{A} \boldsymbol{D}^{\frac{1}{2}} \boldsymbol{D}^{\frac{1}{2}} \boldsymbol{A}^{\prime}=\boldsymbol{P} \boldsymbol{P}^{\prime}$ with $\boldsymbol{P}=\boldsymbol{A} \boldsymbol{D}^{\frac{1}{2}}$. The resulting matrix $\boldsymbol{P}$ can now be used to orthogonalize error terms of the measurement equation $\boldsymbol{\epsilon}_{t}$ in

$$
\boldsymbol{e}_{t}=\boldsymbol{P}^{-1} \boldsymbol{\epsilon}_{t}
$$

The moving average representation of the VAR process for the point of time $t+s$ can be written as

$$
\boldsymbol{y}_{t+s}=\boldsymbol{e}_{t+s}+\boldsymbol{\Psi}_{1} \boldsymbol{e}_{t+s-1}+\boldsymbol{\Psi}_{2} \boldsymbol{e}_{t+s-2}+\ldots+\boldsymbol{\Psi}_{s} \boldsymbol{e}_{t}+\ldots
$$

this leads to

$$
\boldsymbol{\Psi}_{s}=\frac{\partial \boldsymbol{y}_{t+s}}{\partial \boldsymbol{e}_{t}^{\prime}}
$$

Individual impulses in response to a shock with a dimension of a one standard deviation result from row $i$ and column $j$ of the matrix $\Psi_{s}$

$$
\frac{\partial \boldsymbol{y}_{i, t+s}}{\partial \boldsymbol{e}_{j t}^{\prime}}
$$

When applying a Cholesky decomposition for identification, impulse response functions may depend on the ordering of endogenous variables. Ordering in the TVCBVAR setup, from not being contemporaneously being affected by covariates to 
being contemporaneously being affected by all covariates:

1. Housing demand \& supply ratio

2. Relative mortgage rate development

3. GDP growth

4. Apartment prices

The match between housing demand \& supply is contemporaneously in quarter $t=0$ assumed to not be affected by innovations in the other variables. Migration decisions are contemporaneously usually not affected by innovations in the other variables. So is the housing stock - usually the construction process takes longer than a quarter, almost finished apartments will be finished, irrespective of any other economic shock.

Mortgage rates depend on interest rate target bands and banks' policies. Monetary authorities are assumed to contemporaneously not react to house price or GDP developments (nevertheless they might react later on). Changing the order of mortgage rates does not affect the results.

GDP growth is assumed to be contemporaneously affected by population and housing stock growth as well as by interest rates. House prices are assumed to not influence GDP growth contemporaneously. Apartment prices react to all innovations of other variables contemporaneously.

\section{Results}

The stock flow literature (see DiPasquale and Wheaton (1994)) ascribes a strong influence to a mismatch between supply for housing and demand for housing on residential property prices. If housing supply expands more than the demand for new housing, an oversupply in housing might be the consequence and prices might go down. If population growth expands more than housing supply, an undersupply in housing might be the consequence and house prices might rise. Therefore it depends which of the two influencing factors expands more than the other, or if they expand at the same relative rate. Over- and undersupply will be approximated by the difference in growth rates between population growth and construction growth (i.e. housing demand \& supply ratio). Growth rates are calculated as quarterly year over year growth rates, to avoid any kind of seasonality in the results.

[[ Figure 2 to be inserted here. ]] 
As can be seen in figure 2 substantial responses of apartment prices to an shock in housing demand \& supply ratio can be observed. The peak effect to a negative shock is $-1,5 \%$ in median house price growth rates $1-1,5$ years after the shock. The response is hump-shaped. The shock is more persistent in the 1980s. The effects are zero again 5 years after the shock. Since the 1990s the shock leaves the system between 3-4 years after the shock. The size of the explained forecast error variance decomposition is almost $50 \%$ in the 1980 s and declines to $35 \%$ in the most recent years (see figure 3). The results are in line with the findings by Degen and Fischer (2009), which report substantial effects of house price increases in reaction to an increase in immigration. They find that two-thirds of price increases can be explained by immigration, using vacancy rates as control.

[[ Figure 3 to be inserted here. ]]

Figure 4 displays the effect of a relative change of mortgage rates of size one standard deviation onto apartment prices. The size of the impulse responses diminishes over time. In the mid-1980s, the median quarterly apartment price growth (peak effect, observed after 5 quarters), was $1.1 \%$ above what would have been experienced without a one standard deviation mortgage rate shock occurring. After the 1990s real estate crisis the peak median response (after 5 quarters) to a one standard deviation shock drops to $0.7 \%$ per quarter, indicating, that a relative mortgage rate shock has less impact on house prices than it used to have in the 1980s (see figure 5). This is a substantial drop by roughly one third. Since the mid 2000s impulse-responses of house prices to a relative mortgage rate shock have increased again to a peak effect (after 5 quarters) of almost 1\%, indicating an increasing effect of monetary policy decisions on house price developments. The observed structural change for responses of house prices to mortgage rate shocks since 1990s might be a consequence of the 1990s real estate crisis (introduction of sophisticated risk management tools, Basel I, risk aversion of banks).

[[ Figure 4 to be inserted here. ]]

The explained variance of house prices by mortgage rate innovations increases to more than $20 \%$ prior to the real estate crisis, and decreases in the median below $20 \%$ at the turn of the century (see figure 3 . It exceeds $20 \%$ again in the most recent years. Mortgage rate effects are persistent in the short run. While the impulse responses decline from their peak effects (which are observed after one year), five years after the mortgage rate shock house prices are still 0,3 percent higher in the median than they would have been without the shock. ${ }^{14}$ The shape of the responses

\footnotetext{
${ }^{14}$ Such a persistence in responses has repeatedly been reported in the literature. Berlemann and Freese (2013) find that interest rate effects on different kind of housing are rather persistent, and loose their significance 3-4 years after the shock. The peak effect in levels is reached after 2 years. Assenmacher and Gerlach (2008) including Swiss data also find a persistent effect of interest rates on property prices on average in their Panel VAR with 17 countries.
} 
changes over time. While in the early 1990s interest rate effects rapidly reduce in size within 2,5 years, since the early 2000s the effects diminish more slowly and smoothly.

[[ Figure 5 to be inserted here. ]]

Orthogonal innovations to GDP growth do have an effect on house price developments for up to two years. The persistence of the GDP shock increases over time. While during the 1980s/early 1990s, a GDP shock affects house prices in the first five quarters and disappears after 1,5 years, GDP shocks become more persistent after the real estate crisis and last for 2 years. During the early 1990s a double dip of house price responses to an unexpected negative GDP shock can be observed apartment price growth declines strongly within the first 1,5 years, and again declines 2,5 years after the shock (see figure 6). Since the 2000s the effect fades out more smoothly again. The explained forecast error variance decomposition of house prices by GDP is low and fluctuates around $5 \% .{ }^{15}$

[[ Figure 6 to be inserted here. ]]

An important question often raised in the literature (see for instance Assenmacher and Gerlach (2008)) is about the impact of real estate downturns on economic growth. Shocking apartment prices and looking at the response of GDP growth over time reveals, that the parameters remain relatively stable over time. After five quarters a trough is reached, with a reduction of GDP growth between -0.12 to - 0.15 percentage points per quarter (see figure 7 ). The median effect fades out within five years. The explained variance of GDP growth by innovations in apartment prices is very low in the 1980 s with $2 \%$ in the median but climbs to $4 \%$ in the 2010 s (see figure 8).

[[ Figure 7 to be inserted here. ]]

[[ Figure 8 to be inserted here. ]]

\footnotetext{
${ }^{15}$ Other studies also Tsatsaronis and Zhu (2004) find (on average) no substantial effect of GDP on house prices. For group 1 countries (where Switzerland belongs to) Tsatsaronis and Zhu (2004) also only find an explained variance of $5 \%$ and less. Goodhart and Hofmann (2008) find on average no effect during normal times and significant responses during house price peaks using a panel VAR. Also Assenmacher and Gerlach (2008) only find a minor explanatory power for GDP on property prices using a panel VAR.
} 


\section{Conclusion}

Swiss house prices have risen strongly in the last decade. We studied the importance of determinants of house price booms and busts for Switzerland over time. The determinants under investigation were user costs (or financing conditions) as expressed by relative mortgage rate changes, demand \& supply in housing and economic growth. We find that any unanticipated change in mortgage rates or the match between population growth and housing supply continue to matter and will most likely affect house price developments strongly.

Comparing the house price booms of the 1980s and the recent boom since the mid 2000s, mortgage rates seem to have had a similar influence on house prices, while the dependence has been weaker in between. The match between housing demand and supply appears to have been more influential in relative terms in the 1980s than it is today, yet also today the explanatory power is very high at $40 \%$. In the 1980 s as well as today the match between housing supply and demand is by far more important than mortgage rate developments. In comparison to mortgage rate and supply/demand effects, GDP growth matters only marginally for explaining house price developments.

Such findings are highly relevant for the current situation in Switzerland, where mortgage rates have reached all time lows in consequence to setting the LIBOR target rate to negative values. At the same time stricter criteria on mortgage availability most likely will increase the average effective mortgage rate to be paid by households. Housing production declines, but not as much as population growth might slow down in consequence to weaker job market conditions in consequence to the strong appreciation of the Swiss Franc in mid January 2015 (repeal of the lower bound) and in consequence to a more restrictive immigration policy (anti-mass immigration initiative), to be in place by 2017. 


\section{References}

Assenmacher, K., and S. Gerlach (2008): "Monetary policy, asset prices and macroeconomic conditions: a panel-VAR study," National Bank of Belgium Working Paper, (149). [back to page 4, 11, 12]

Belke, A. H., And W. ORTh (2007): "Global excess liquidity and house prices-a VAR analysis for OECD countries," Ruhr Economic Paper, (37). [back to page 4]

Berlemann, M., And J. Freese (2013): "Monetary policy and real estate prices: a disaggregated analysis for Switzerland," International Economics and Economic Policy, 10(4), 469-490. [back to page 4, 11]

Borowiecki, K. J. (2009): "The determinants of house prices and construction: an empirical investigation of the Swiss housing economy," International Real Estate Review, 12(3), 193-220. [back to page 4]

Bourassa, S., M. Hoesli, and D. Scognamiglio (2010): "Housing finance, prices, and tenure in Switzerland," Journal of Real Estate Literature, 18(2), 263282. [back to page 4]

Brown, M., And B. Guin (2013): How Risky are Residential Mortgages in Switzerland? Swiss Institute of Banking and Finance. [back to page 4]

Carter, C. K., and R. Kohn (1994): "On Gibbs Sampling for State Space Models," Biometrika, 81(3), 541-553. [back to page 8]

Degen, K., And A. M. Fischer (2009): "Immigration and Swiss house prices," . [back to page 4,11$]$

Del Negro, M., And F. Schorfheide (2011): "Bayesian Macroeconometrics," The Oxford Handbook of Bayesian Econometrics, pp. 293-389. [back to page 7]

DiPasquale, D., and W. C. Wheaton (1994): "Housing market dynamics and the future of housing prices," Journal of urban economics, 35(1), 1-27. [back to page 5, 10]

GambetTi, L. (2005): "Technology shocks and the response of hours worked: timevarying dynamics matter," Manuscript, Universitat Pompeu Fabra, Barcelona, Spain. [back to page 7]

Goodhart, C., and B. Hofmann (2008): "House prices, money, credit, and the macroeconomy," Oxford Review of Economic Policy, 24(1), 180-205. [back to page $4,12]$

Hamilton, J. D. (1994): Time Series Analysis. Cambridge University Press. [back to page 7]

Hott, C., And P. Monnin (2008): "Fundamental real estate prices: an empirical estimation with international data," The Journal of Real Estate Finance and Economics, 36(4), 427-450. [back to page 3, 5] 
Kim, C.-J., And C. R. Nelson (2003): State-Space Models with Regime Switching: Classical and Gibbs-Sampling Approaches with Applications, vol. 1. MIT Press Books. [back to page 7]

Koop, G., And D. Korobilis (2010): "Bayesian Multivariate Time Series Methods for Empirical Macroeconomics," Foundations and Trends $(R)$ in Econometrics, 3(4), 267-358. [back to page 7]

Steiner, E. (2010): "Estimating a stock-flow model for the Swiss housing market," Swiss Journal of Economics and Statistics (SJES), 146(III), 601-627. [back to page 3,5$]$

Tsatsaronis, K., And H. Zhu (2004): "What drives housing price dynamics: cross-country evidence," BIS Quarterly Review, March. [back to page 4, 12] 
Figure 1: Swiss apartment prices, housing demand \& supply, mortgage rates and GDP growth over time

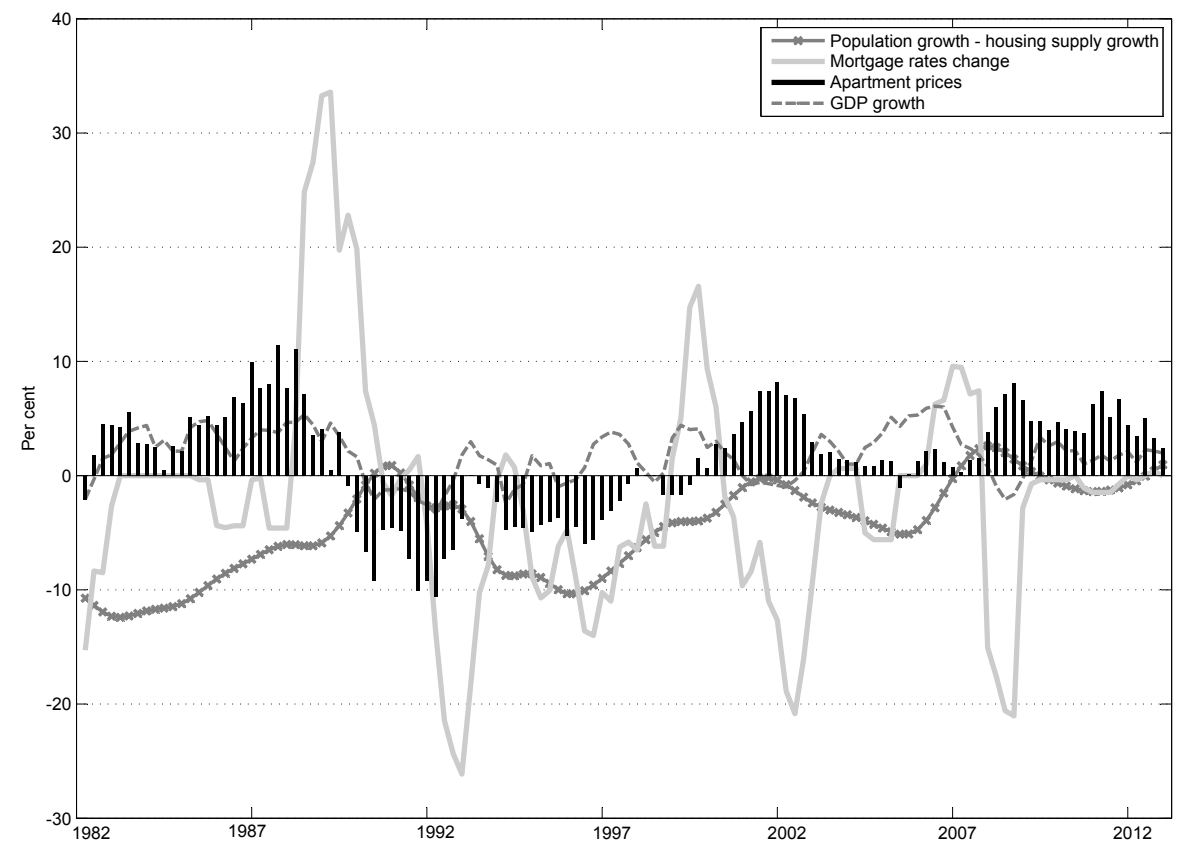

The figure displays the quarterly development of apartment prices, the difference between population growth and housing stock growth, mortgage rate changes and GDP growth from Q1 1982 to Q2 2014. The $y$-axis displays values in percentage terms. Growth rates are depicted in quarter-over-previousyear-quarter rates. The bars show apartment price growth rates. The solid light grey line depicts relative changes in mortgage rates. The dark grey line with crosses displays the difference between population growth and housing stock growth. The dashed light grey line represents GDP growth. 
Figure 2: Response of apartment prices to a shock on housing demand \& supply ratio
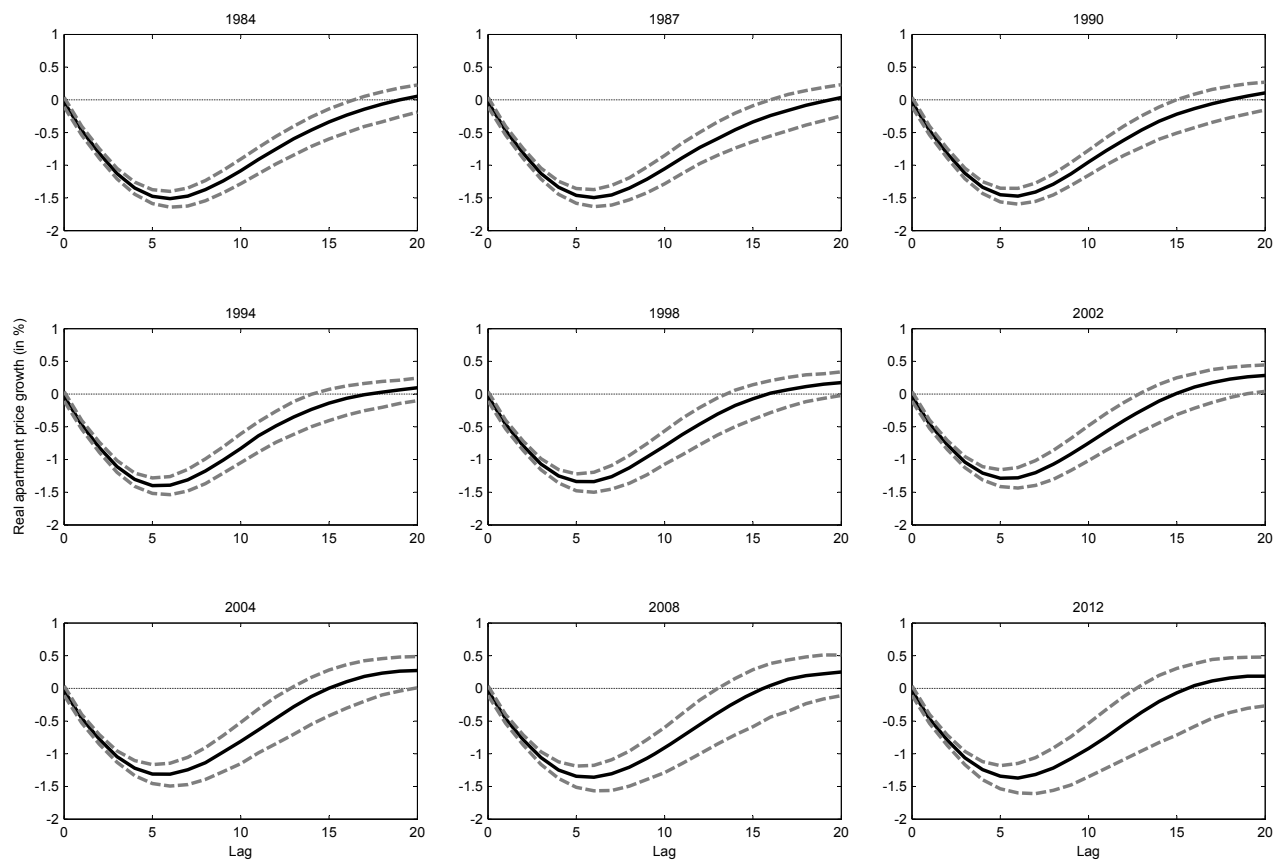

This figure represents the impulse response functions of the reaction of apartment prices to a negative shock on housing demand $\&$ supply ratio. Such a shock could be caused by an unanticipated decline in population growth or by an unanticipated increase in construction of new apartments. The magnitude of the shock is set to one standard deviation. The x-axis depicts the lags as measured in quarters. The ordinate displays the responses in percentage points. The results are based on the previously described use of a TVC-BVAR. Each plot refers to a specific observation point. For each point in time results a different impulse response function because of the time-varying estimation. The continuous line represents the median and the dashed lines the highest propensity density interval-error range with one standard deviation. 
Figure 3: Variance decomposition of apartment prices

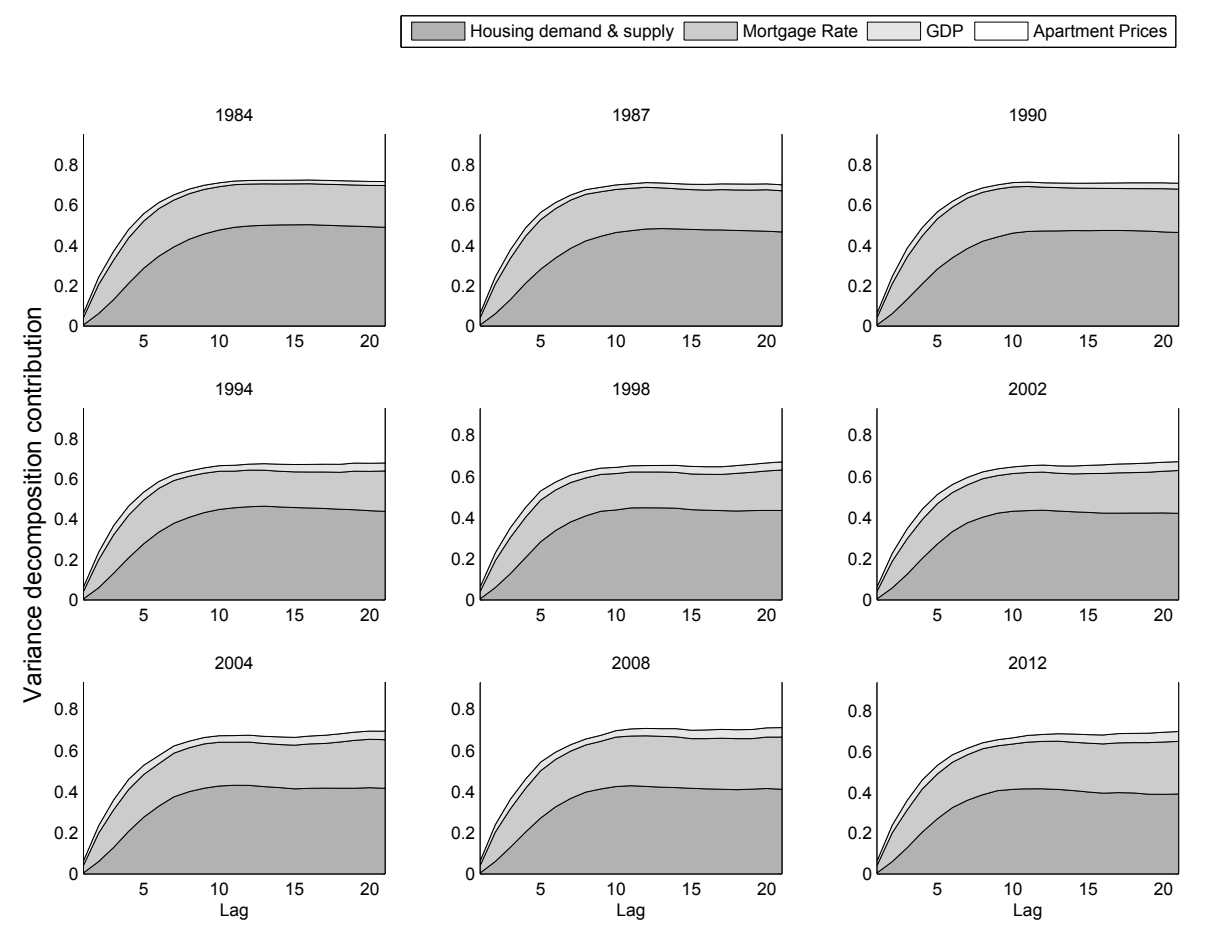

This figure represents the forecast error variance decomposition of the reaction of apartment prices to negative shocks on housing demand 83 supply ratio, relative mortgage rate developments and GDP growth. The magnitude of the shock is set to one standard deviation. The x-axis depicts the lags as measured in quarters. The ordinate displays the explained forecast error variance in percentage points. The results are based on the previously described use of a TVC-BVAR. Each plot refers to a specific observation point. For each point in time results a different variance decomposition because of the time-varying estimation. Stacked areas depict median responses. 
Figure 4: Response of apartment prices to a relative change in mortgage rates (i.e. user costs)
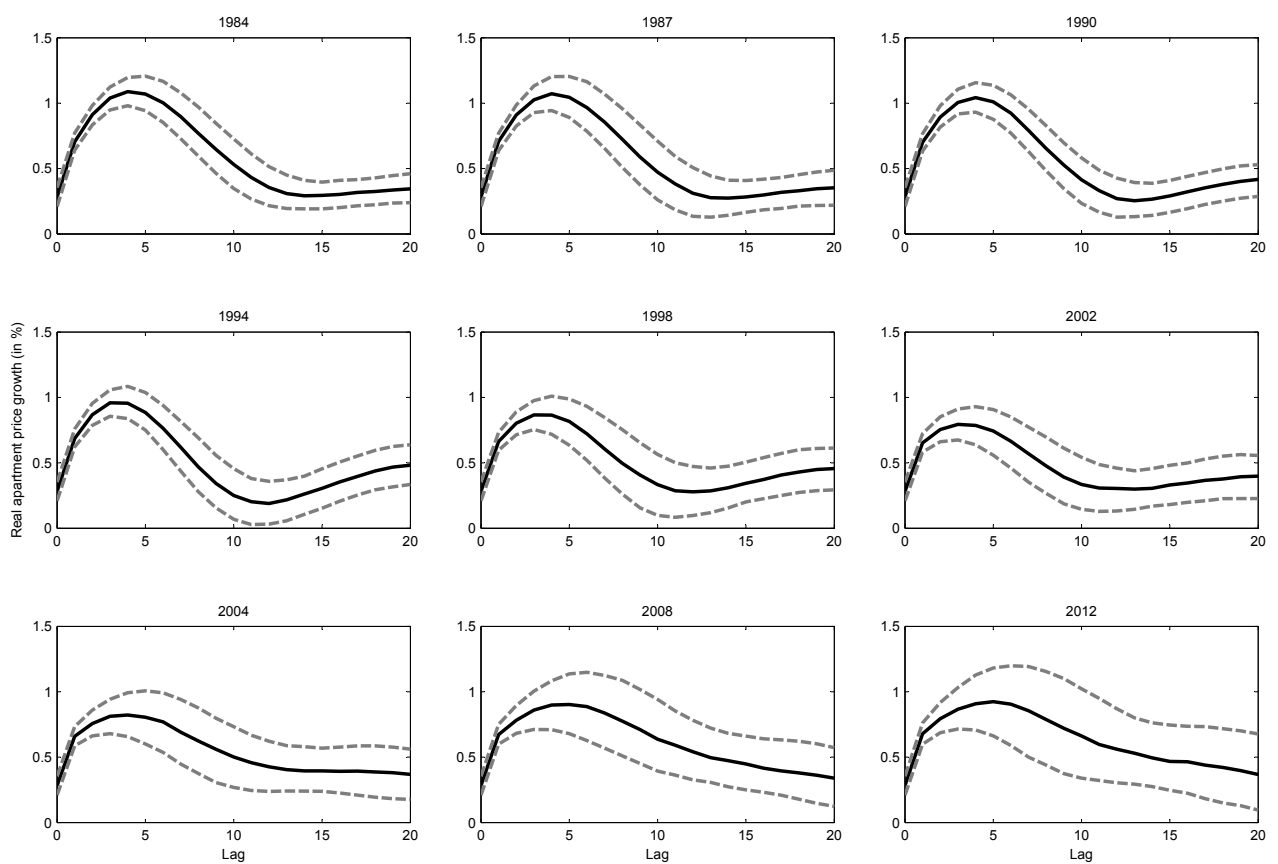

This figure represents the impulse response functions of the reaction of apartment prices to a negative shock in relative mortgage rates changes (i.e. user costs). Such a shock could be caused by an unanticipated decline in the relative change in mortgage rates. The magnitude of the shock is set to one standard deviation. The $x$-axis depicts the lags as in quarters. The ordinate displays the responses in percentage points. The results are based on the previously described use of a TVC-BVAR. Each plot refers to a specific observation point. For each point intime results a different impulse response function because of the time-varying estimation. The continuous line represents the median and the dashed lines the highest propensity density interval-error range with one standard deviation. 
Figure 5: Peak effect (after 5 quarters) of apartment price responses to a relative change in mortgage rates (i.e. user costs)

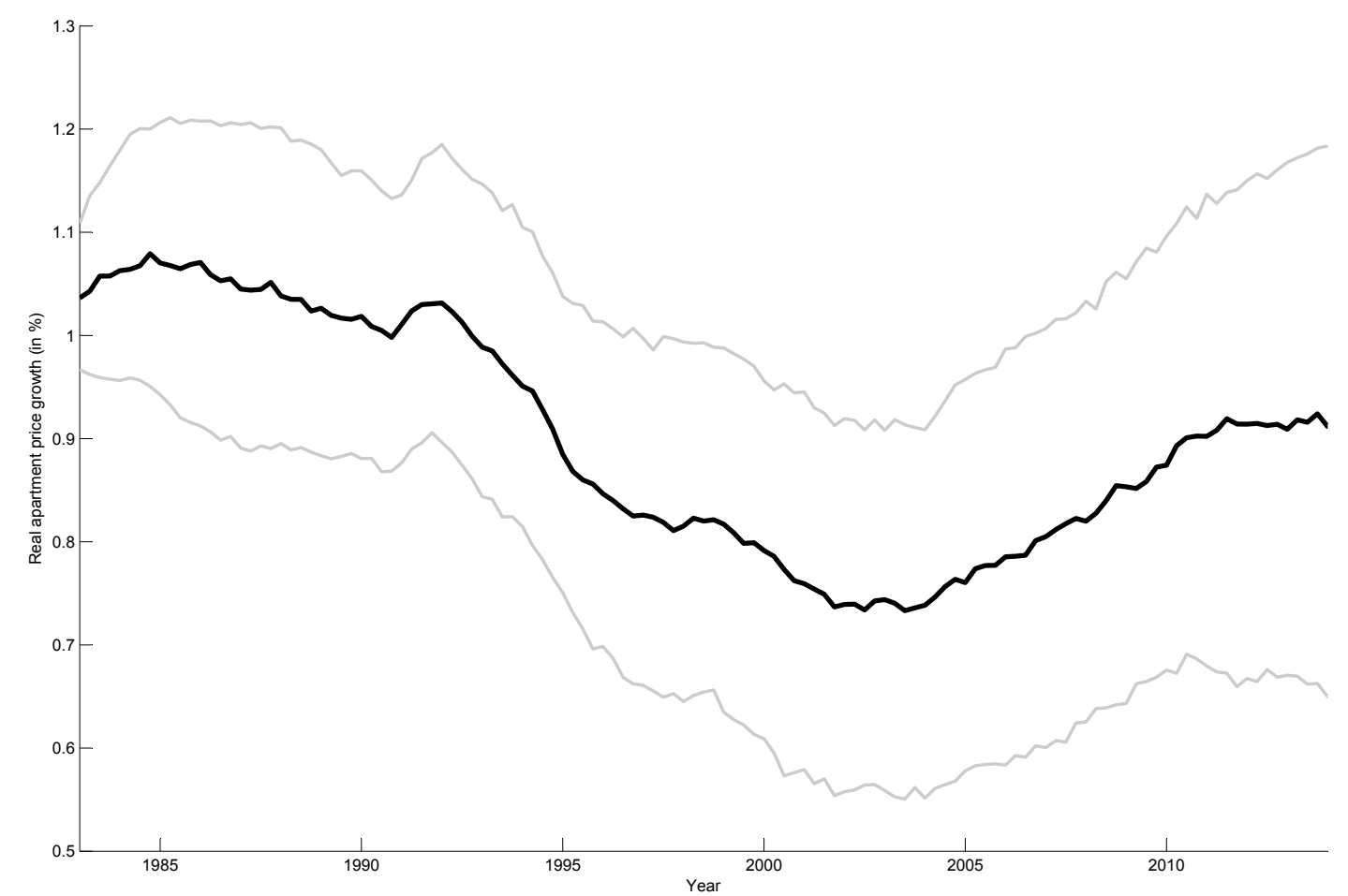

This figure represents the movement of impulse responses over time, measured 5 quarters after the shock of apartment prices to a negative shock in relative mortgage rates changes (i.e. user costs). The magnitude of the shock is set to one standard deviation. The $x$-axis depicts the lags as in quarters. The ordinate displays the responses in percentage points. The results are based on the previously described use of a TVC-BVAR. The continuous line represents the median and the grey lines the highest propensity density interval-error range with one standard deviation. 
Figure 6: Response of apartment prices to a shock on GDP growth
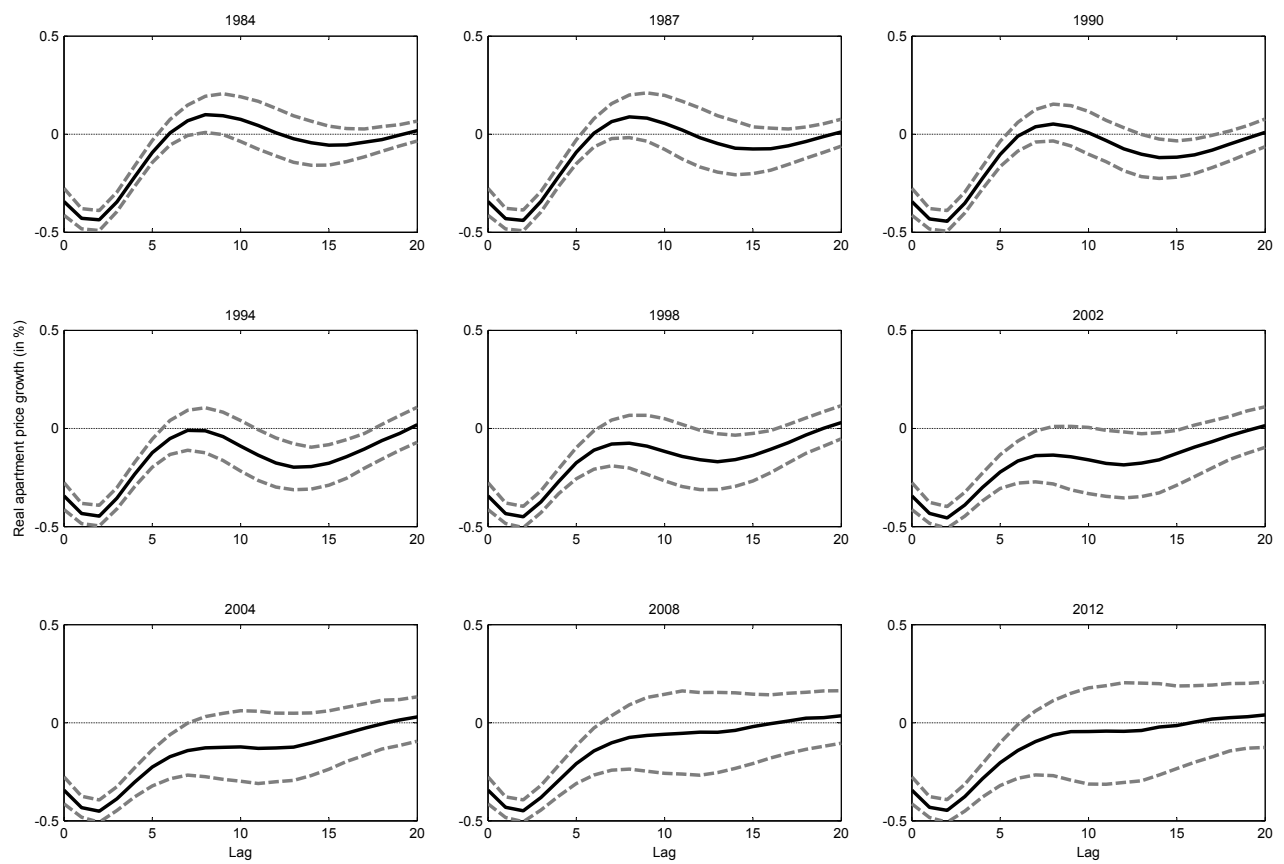

This figure represents the impulse response functions of the reaction of apartment prices to a negative shock in GDP growth. Such a shock could be caused by an unanticipated decline in GDP growth. The magnitude of the shock is set to one standard deviation. The x-axis depicts the lags as in quarters. The ordinate displays the responses in percentage points. The results are based on the previously described use of a TVC-BVAR. Each plot refers to a specific observation point. For each point in time results a different impulse response function because of the time-varying estimation. The continuous line represents the median and the dashed lines the highest propensity density interval-error range with one standard deviation. 
Figure 7: Response of GDP growth to a shock on apartment prices
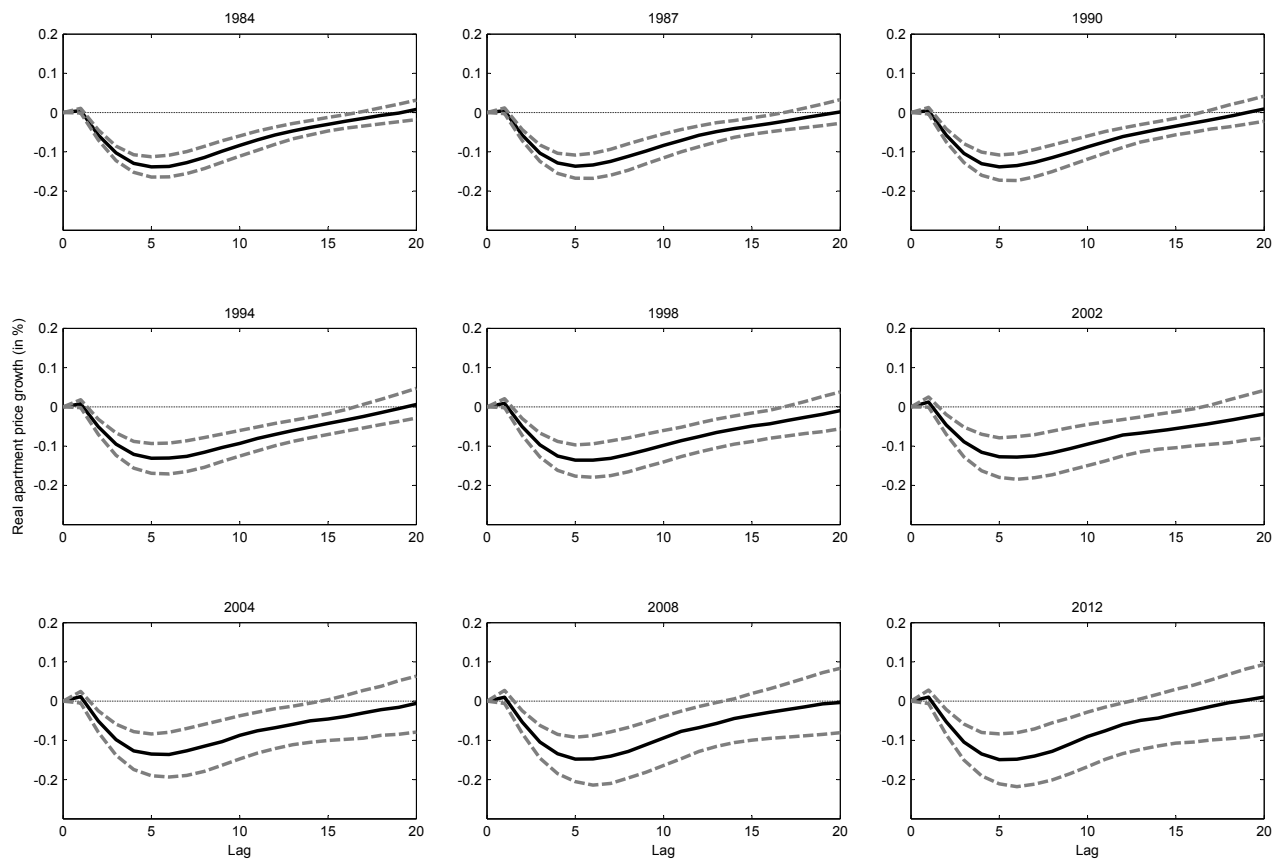

This figure represents the impulse response functions of the reaction of GDP growth to a negative shock in apartment prices growth. Such a shock could be caused by an unanticipated decline in apartment prices. The magnitude of the shock is set to one standard deviation. The x-axis depicts the lags as in quarters. The ordinate displays the responses in percentage points. The results are based on the previously described use of a TVC-BVAR. Each plot refers to a specific observation point. For each point in time results a different impulse response function because of the time-varying estimation. The continuous line represents the median and the dashed lines the highest propensity density interval-error range with one standard deviation. 
Figure 8: Variance decomposition of GDP growth to a shock on apartment prices
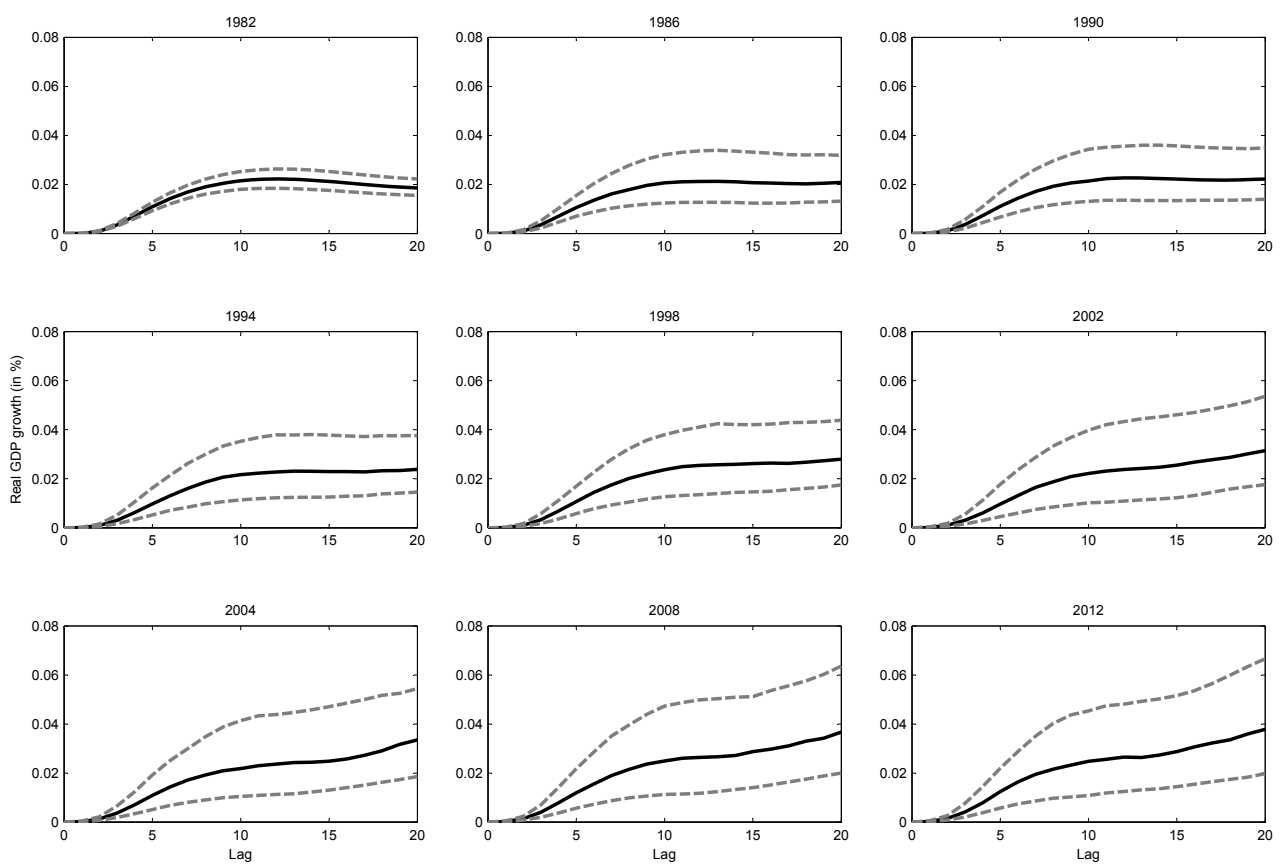

This figure represents the forecast error variance decomposition of the reaction of GDP growth to a negative shock in apartment prices growth. Such a shock could be caused by an unanticipated decline in the relative change in mortgage rates. The magnitude of the shock is set to one standard deviation. The $x$-axis depicts the lags as in quarters. The ordinate displays the explained variance in percentage points. The results are based on the previously described use of a TVC-BVAR. Each plot refers to a specific observation point. For each point of time results a different forecast error variance decomposition because of the time-varying estimation. The continuous line represents the median and the dashed lines the highest propensity density interval-error range with one standard deviation. 